\title{
New Reservoir Grading Method for Tight Gas Reservoir - One Case Study in Kekeya Block, Tuha Basin, China
}

\author{
Fangfang $\mathrm{Wu}^{1}{ }^{1, *}$, Jinchuan $\mathrm{Zhang}^{1}$, Liuzhong $\mathrm{Li}^{2}$ and Jinlong $\mathrm{Wu}^{3}$
}

${ }^{I}$ Schoole of Energy Resources, China University of Geosciences (Beijing), No. 29 Xueyuan Road, Haidian District, Beijing, 100083, P.R. China; ${ }^{2}$ Research Institute of Petroleum Exploration \& Development, PetroChina Tuha Oilfield Company, Hami 839009, P.R. China, ${ }^{3}$ Schlumberger China, No.14 Jiuxianqiao Road, Chaoyang District, Beijing, 100015, P.R. China

\begin{abstract}
Tight sand reservoir is usually characterized by high heterogeneity and complex pore structure, which makes the permeability calculation a big challenge and leads to difficulties in reservoir classification and productivity evaluation. First, five different Hydraulic Flow Units and respective Porosity-permeability relations were built based on core dataset from Kekeya block, Tuha Basin; and then with BP Neutron Network method, flow unit was classified for un-cored intervals using normalized logging data, and permeability was calculated accordingly. This improved the accuracy of permeability calculation and helped a lot on un-cored reservoir evaluation. In addition, based on porosity, permeability and flow unit type, a new reservoir grading chart was set up by incorporating the testing or production data, which provides important guidance for productivity prediction and reservoir development.
\end{abstract}

Keywords: BP neutral network, Hydraulic flow unit, Logging data, Permeability, Reservoir grading, Tight sand.

\section{INTRODUCTION}

Tight sand reservoir usually refers to sandstone with porosity less than $12 \%$, absolute permeability less than $1 \mathrm{mD}$, water saturation more than $40 \%$ and pore throat radius less than $0.5 \mu \mathrm{m}$ [1]. Tight sand reservoirs are characterized by complicated pore structure, different kinds of clay minerals, high capillary pressure and high water saturation, which affect reservoir permeability and productivity and bring great difficulties to reservoir grading evaluation using conventional logs. Porosity and permeability are key parameters for reservoir evaluation; porosity can be easily acquired by nuclear magnetic resonance tool or calibration with core dataset. In conventional reservoir, permeability has good correlation with porosity, which can be calculated easily. However, in tight sand reservoirs, beside the intergranular residual pores, pore spaces also include intragranular dissolution pores, micro pores and micro fractures. These different spaces are connected by the fine throats in between [2], which makes the relationship between permeability and porosity no longer follow simple linear relation. In order to get more accurate permeability for reservoir grading, it is necessary to classify the reservoir into different types [3-5], and then set up the permeability-porosity relations respectively.

The study area is located in Tuha basin, northwestern of China. The target formation is tight sand reservoir of Jurassic tight sand reservoir, which is mainly debris-feldspar and feldspar-debris sandstone with average porosity of $6 \%$ and average permeability of $0.45 \mathrm{mD}$. In order to better evaluate

*Address correspondence to this author at the School of Energy Resources, China University of Geosciences, No. 29 Xueyuan Road, Haidian District, Beijing, 100083, P.R.China; Tel: 13521435921;

E-mail: wufang66@163.com the tight sand reservoir, the authors proposed an integrated method. Starting with core data analysis, the reservoir was classified into five different types of Hydraulic Flow Units (HFUs), and for each unit, permeability calculation model can be regressed. For un-cored intervals, HFUs can be classified by using BP Neutron Network, and the permeability can then be calculated accordingly to respective models. Finally, reservoir grading chart was built up by combining porosity, permeability, hydraulic flow unit and production data.

\section{HYDRAULIC FLOW UNIT FUNDAMENTALS}

Hydraulic flow unit was first proposed by Amaefule et al. in 1993 [6]. It was defined as reservoir unit with similar fluid flowing characteristics. Reservoir Quality Index (RQI) and Flow Zone Indicator (FZI) were also defined by Amaefule et al. according to modified Kozeny - Catmen formula, RQI was defined as:

$R Q I=0.0314 \sqrt{\frac{K}{\phi_{e}}}$

FZI was defined as:

$F Z I=\frac{R Q I}{\phi_{e}}$

$\phi_{z}$ is the ratio of pore volume and grain volume,

$\phi_{z}=\frac{\phi_{e}}{1-\phi_{e}}$

Then,

$R Q I=\phi_{z} F Z I$ or $\log (R Q I)=\log \left(\phi_{z}\right)+\log (F Z I)$ 
Since permeability and porosity can be measured from core samples, $\phi_{z}$, RQI, FZI can be obtained using the above equations. In the RQI- $\phi_{z}$ dual logarithmic diagram, samples of similar FZI values will fall on one line with slope of 1 and intercept of $\log (F Z I)$. Samples on the same lines have similar pore-throat feature and belong to one HFU.

\section{HYDRAULIC FLOW UNIT (HFU) BASED ON CORE DATA}

FZI is the integrated response of rock minerals and porethroat features, and it is a unique parameter for each hydraulic unit, which was widely used in HFU classification [7, 8]. In this case, RQI and FZI were calculated based on coremeasured porosity and permeability of 221 samples from 8 wells. According to dual logarithmic diagram of RQI- $\phi_{z}$, cumulative probability curve of FZI and FZI histogram [9], 5 types of hydraulic units can be identified, namely HU1, HU2, HU3, HU4 and HU5.

Dual logarithmic diagram of RQI- $\phi_{z}$ (Fig. 1): As mentioned before, samples of similar FZI values will fall on one line with slope of 1 and intercept of $\log (F Z I)$. While samples of obviously different FZI values will fall on different lines which have the same slope but different intercepts.

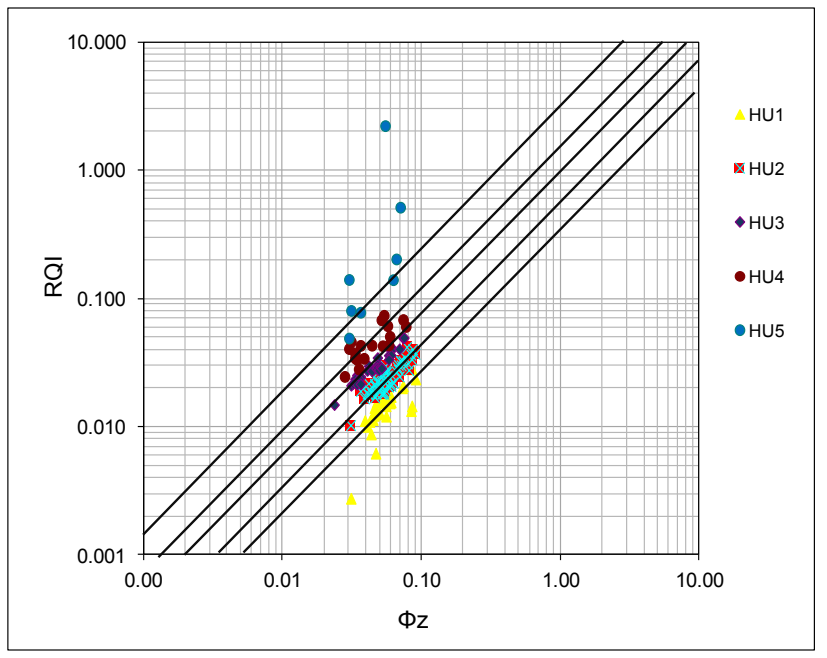

Fig. (1). Dual logarithmic diagram of RQI- $\varphi_{z}$.

FZI histogram (Fig. 2): Since FZI distribution is the superposition of multiple lognormal distributions, so FZI histogram can show normal distribution of several flow units and provide them with the corresponding FZI value. However, it is difficult to distinguish single HFU from the overlap region of the histogram.

Cumulative probability curve of FZI (Fig. 3): Due to the presence of random measurement error of core analysis, the FZI values usually distribute around their true mean values. On the cumulative probability graph, samples of normal distribution should fall into a straight line. Each HFU has its own normal distribution, so different HFU should fall into straight lines of different slope.

In addition, characteristics of each HFU were summarized by incorporating thin section and mercury injection data.

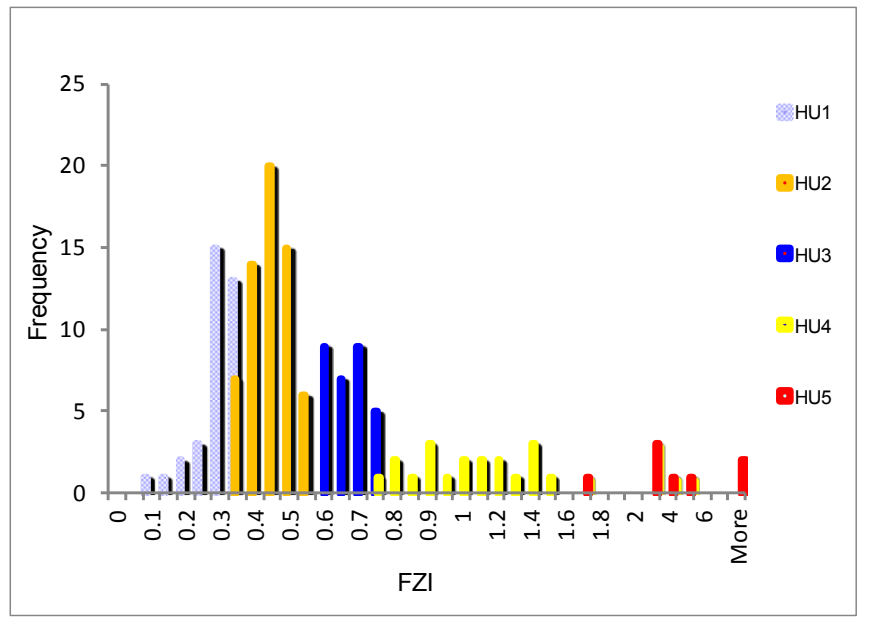

Fig. (2). FZI histogram distribution.

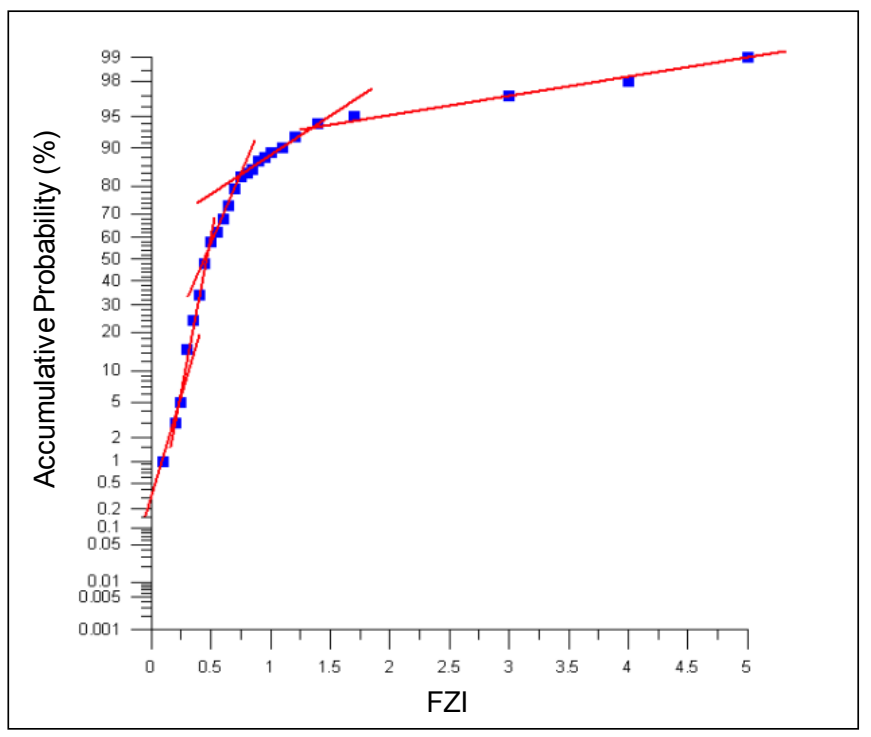

Fig. (3). Cumulative probability curves of FZI.

(1) HU1: FZI $<0.33$; few intergranular residual pores, some micropores in clay matrix, occasional intragranular dissolution pores, poor connectivity, displacement pressure is more than $0.1 \mathrm{MPa}$.

(2) HU2: $0.33<\mathrm{FZI}<0.5$; some intragranular dissolution pores, poor connectivity, displacement pressure is more than $0.09 \mathrm{MPa}$.

(3) HU3: $0.5<$ FZI $<0.7$; many intergranular residual pores and intragranular dissolution pores, big pore throat, good connectivity, displacement pressure is more than $0.06 \mathrm{MPa}$.

(4) HU4: $0.7<\mathrm{FZI}<1.6$; many intergranular residual pores and intragranular dissolution pores, many micro fractures, big pore throat, good connectivity, displacement pressure is about $0.04 \mathrm{MPa}$.

(5) HU5: FZI $>1.6$; dissolution pores are not developed and displacement pressure is high (about $0.1 \mathrm{MPa}$ ), while open fractures are developed, which enhanced the reservoir permeability greatly. 


\section{PERMEABILITY CALCULATION BASED ON FLOW UNIT}

Since each type HFU has similar fluid-flow characteristics, permeability and porosity show good correlation for each flow unit. Based on the HFU obtained from core data, the permeability calculation models were built up respectively (Fig. 4).

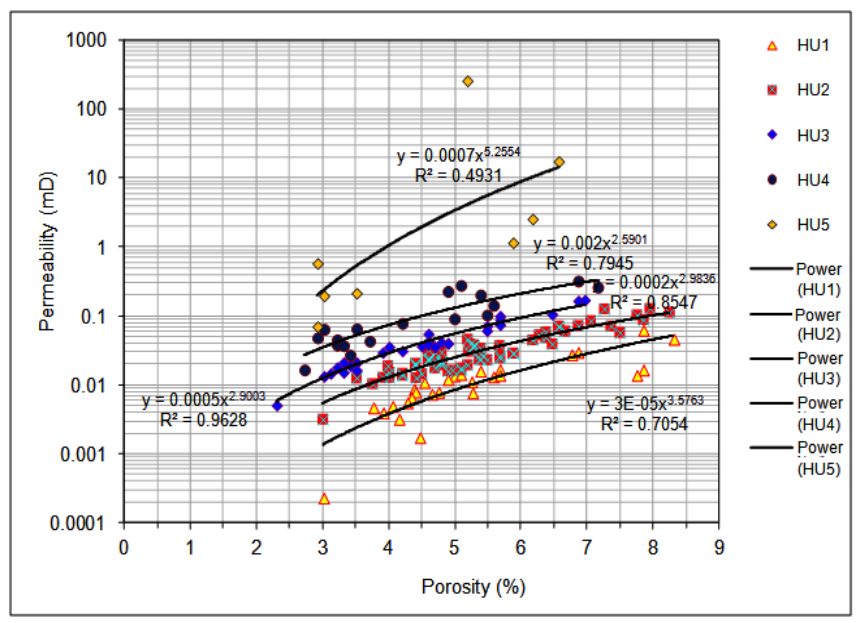

Fig. (4). Permeability-porosity model based on HFU.

Permeability (K) calculation of HU1:

$K=0.00003 \times P O R^{3.57367}, R^{2}=0.7054$

Permeability (K) calculation of HU2:

$K=0.0002 \times P O R^{2.9836}, R^{2}=0.8547$

Permeability (K) calculation of HU3:

$K=0.0005 \times P O R^{2.9003}, R^{2}=0.9528$

Permeability (K) calculation of HU4:

$K=0.002 \times P O R^{5.25016}, R^{2}=0.7945$

Permeability (K) calculation of HU5:

$K=0.0007 \times P O R^{5.2554}, R^{2}=0.4931$

\section{PERMEABILITY CALCULATION BASED ON LOG DATA}

As we know, core data is limited because it's time consuming and expensive, while continuous log data is easier to get and it contains a lot of information. In this paper, we used BP (Back Propagation) neural network technique to classify the logs into different HFUs.

BP algorithm is called Error Back-Propagation algorithm. An interpretation model can be built up by learning and training on a given dataset. The basic idea of back propagating network output error is that it continues to adjust and modify the connection weights and thresholds of the network to minimize the errors. It has self-organizing, self-learning, adaptive, fault tolerance and anti-interference ability, and has been used to predict carbonate log facies and identify volcanic lithologies [10,11].
Using logging data to identify HFU mainly includes four steps: (1) Match the core depth to the log depth, analyze the correlation between FZI and different logging curves and determine the logs sensitive to flow unit type; (2) Normalize the sensitive log curves; (3) Establish the training dataset by incorporating the normalized log data and the flow unit type, get the interpretation model between the log curves and the flow unit type by training the dataset using BP neutral network technique; (4) Apply the interpretation model to the logs of un-cored intervals or wells to identify the HFU type.

Self-checking was done for the training dataset which contains 221 samples, and the coincidence rate was above $85 \%$ (Fig. 5). According to BP neutral network model, 19 wells of HFU type were identified using log data, then permeability was calculated based on the permeability-porosity models set up from core dataset. Fig. (6) shows that the calculated permeability agrees well with the core measured permeability.

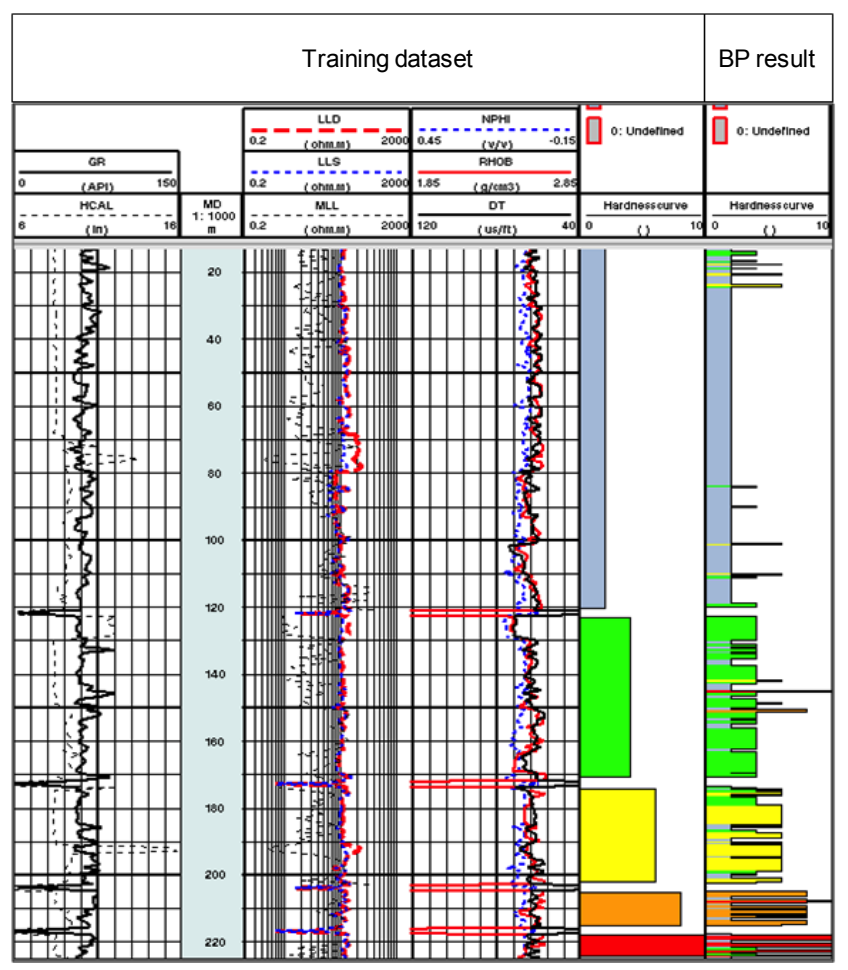

Fig. (5). Self-checking result of Flow Units.

\section{NEW RESERVOIR GRADING METHOD}

On the basis of HFU classification and permeability calculation, we classified the reservoir into different grades by integrating the testing or production data, and built up a useful grading chart which can help to grade the reservoir productivity quickly and effectively.

First, cutoff values of effective reservoir were analyzed by using Distribution Function method and Abandon method [12]. Fig. (7) is the frequency distribution diagram of porosity where, the black line represents samples of dry interval, and the red line represents the samples of producing interval, the cross point of the two curves will be the cutoff according to Distribution Function method, which is about $4.7 \%$. 


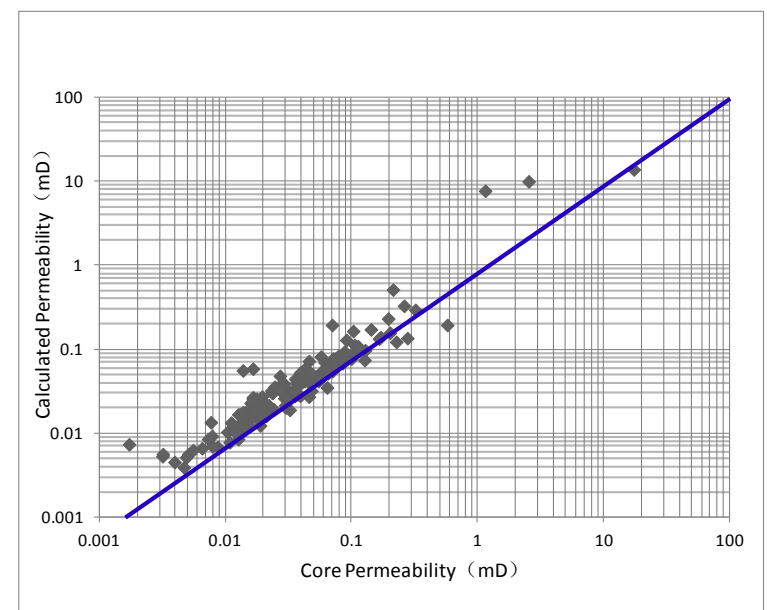

Fig. (6). Permeability from HFUs versus permeability from core analysis.

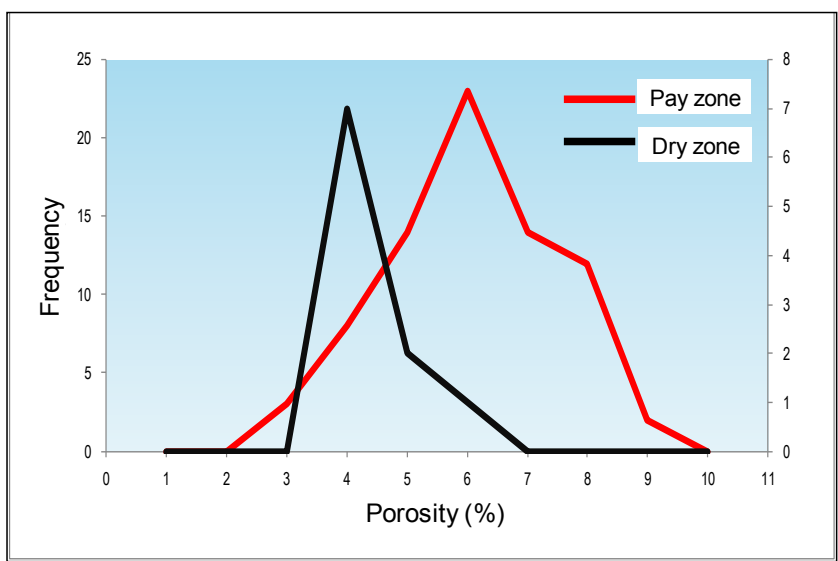

Fig. (7). Frequency distribution diagram of porosity.

Fig. (8) is the porosity histogram of testing intervals, and it is believed that small pores which occupy about $20 \%$ of the pore spaces contribute very little to the production which can be ignored. According to the two methods, the porosity cutoff of the first type of HFU is about $4.5 \%$ and $3.0 \%$ for the fifth type of HFU.

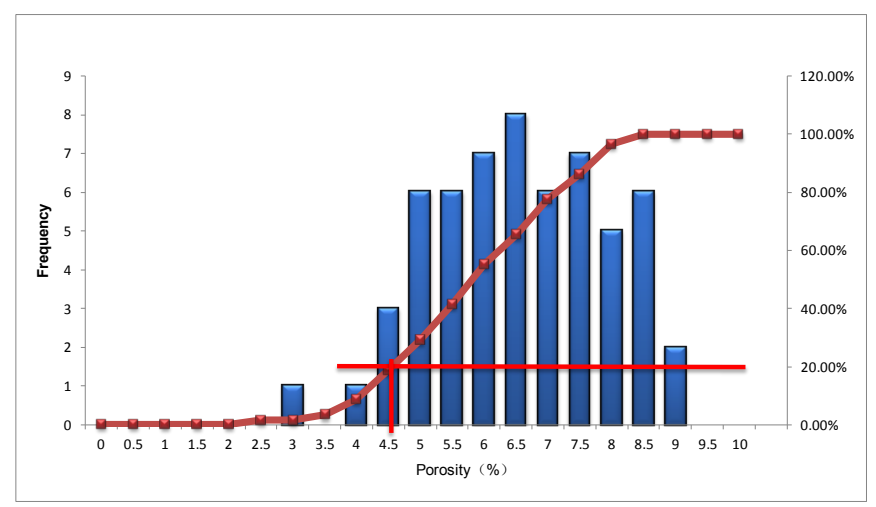

Fig. (8). Frequency distribution histogram of porosity within testing intervals.

Draw a vertical line where porosity equals to $4.5 \%$ and $3.0 \%$ on the cross plots of permeability and porosity for each type of HFUs, you can get the permeability cutoffs corresponding to different types of HFUs. And by connecting the intersecting points together you can get the continuous cutoff line of effective reservoir, which is the black oblique line on the left bottom (Fig. 9). If the porosity and permeability fall into the area below the black line, it will be difficult to produce any gas even after stimulation, which can be classified into Type III. And then, by normalizing the production data, we can find the line corresponding to economic production that is the red oblique line on the right top. If the porosity and permeability falls into the area above the red line, it would be easier to produce economically, which can be classified into Type I. If the points fall between the red and black oblique line, the reservoir can produce some gas, but it is still difficult to break even, which is classified into Type II.

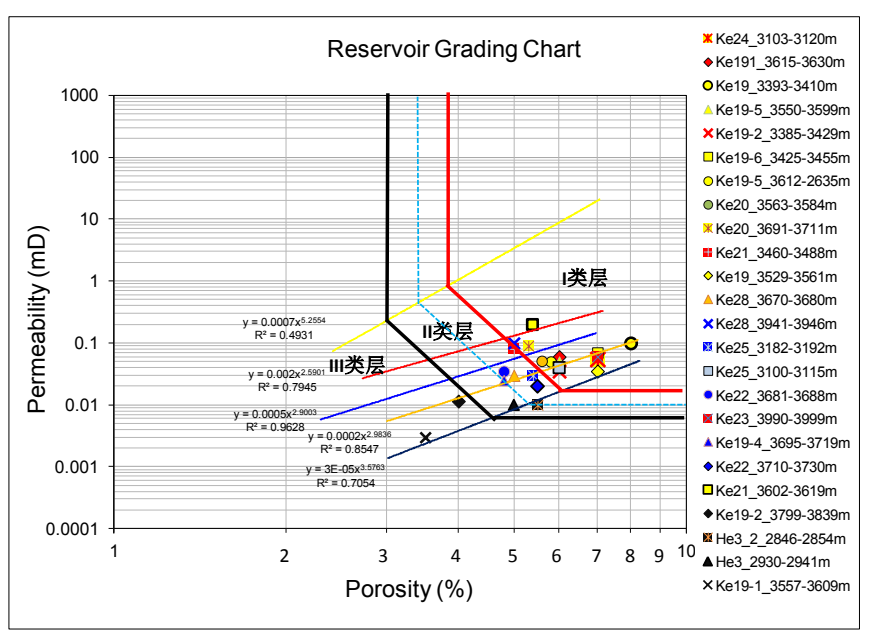

Fig. (9). Reservoir Grading Chart based on HFUs.

Fig. (10) shows the grading result of Well A. From the result we can see that, the porosity of the testing interval is higher than $7 \%$, but the permeability is relatively low, and so most intervals are classified into the first and second type of HFUs. However, accordingly to grading chart, the porosity and permeability of this interval fall into Type I area, which means that this interval can be produced economically after stimulation. The testing result shows that, after acidizing, this interval can produce $53682 \mathrm{~m}^{3}$ of gas and $19.76 \mathrm{~m}^{3}$ of oil per day, which matches our grading result very well.

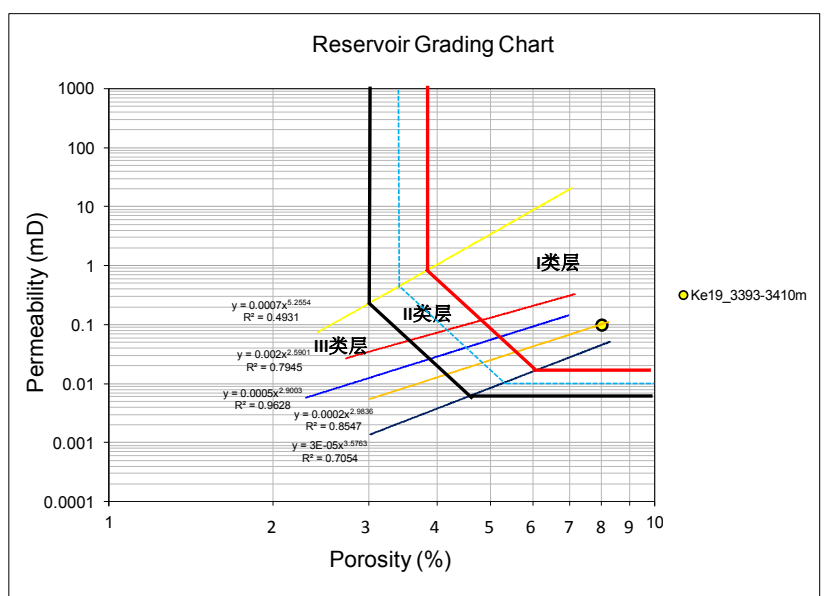

Fig. (10). Grading result of one well. 


\section{CONCLUSION}

Tight sand reservoir must be classified into different types in order to get the reservoir properties more accurately and effectively due to the high heterogeneity and complex structure.

Based on core dataset, we can classify the reservoir into different types of HFUs, and build up the permeability calculation models for every HFU accurately. Permeability of uncored interval or wells can be calculated by propagating the HFUs method using BP Neutron Network technique.

A new reservoir grading method has been proposed by integrating the porosity, permeability, HFUs and testing data. And this new approach has been implemented widely in the tight sand evaluation of Kekeya block, and provided valuable information for production prediction and reserve exploration.

\section{CONFLICT OF INTEREST}

The authors confirm that this article content has no conflict of interest.

\section{ACKNOWLEDGEMENTS}

We would like to thank Tuha Oilfield for supporting this study and for granting permission to publish the results.

\section{REFERENCES}

[1] J.Y. Liu, Z.X. Ma, and S.Y. Sun, "Present research situation and prospects of tight gas sands", Natural Gas Geoscience, vol. 19, pp. 316-319, 2008.

[2] J.Yang, Y.L. Kang, Q.G. Li, and H. Zhang, "Characters of microstructure and percolation in tight sandstone gas reservoirs", $A d$ vances in Mechanics, vol. 38, pp. 229-236, 2008.

[3] J.C. Porras, and O. Campos, "Rock typing: a key for petrophysical characterization and definition of flow units, Santa Barbara field, eastern Venezuela basin", In: SPE 69458 at SPE Latin American and Caribbean Petroleum Engineering Conference, Buenos Aires, 2001.

[4] G. Guo, M.A. Diaz, F. Paz, J. Smalley, and E.A. Waninger, "Rock typing as an effective tool for permeability and water saturation modeling: a case study in a clastic reservoir in the orient basin", In: SPE 97033 at Annual Technical Conference and Exhibition, Dallas, Texas, 2005

[5] J.A. Rushing, "Rock typing -keys to understanding productivity in tight gas sands", In: SPE 114164 at SPE Unconventional Reservoirs Conference, Keystone, Colorado, USA, 2008.

[6] J.O. Amaefule, M. Altunbay, D. Tiab, D.G. Kersey, and D.K. Keelan, "Enhanced reservoir description: using core and log data to identify hydraulic (flow) units and predict permeability in un-cored intervals/wells", In: SPE 26436 at the SPE Annual Technical Conference and Exhibition, Houston, 1993

[7] C. Aguilar, H.A. Govea, and G. Rincon, "Hydraulic unit determination and permeability prediction based on flow zone indicator using cluster analysis", In: SPE 169307 at SPE Latin America and Caribbean Petroleum Engineering Conference, Maracaibo, Venezuela, 2014.

[8] M.B. Shahvar, R. Kharrat, and M. Matin, "Applying flow zone index approach and artificial neural networks modeling technique for characterizing a heterogeneous carbonate reservoir using dynamic data: case study of an Iranian reservoir", In: SPE 132898 at the Trinidad and Tobago Energy Resources Conference Held in Port of Spain, Trinidad, 2010.

[9] M. Abbaszadeh, H. Fujii, and F. Fujimoto, "Permeability prediction by hydraulic flow units - theory and applications", In: SPE 30158 First Presented at the 1995 SPE Petrovietnam Conference, Hochiminh, 1995.

[10] H. Tang, N. Toomey, and W.S. Meddaugh, "Using an artificialneural-network method to predict carbonate well log facies successfully", In: SPE123988 Presented at the SPE Annaul Technical Conference and Exhibition, New Orleans, 2009.

[11] C.H. Fan, Z.L. Liang, Q.R. Qin, L. Zhao, and J. Zuo, "Identification of volcanic rock lithology by using genetic bp neural network based on logging parameters - by taking carboniferous volcanic rocks in Zhongguai uplift of northwestern margin of Junggar basin for instance", Journal of Oil and Gas Technology, vol. 34, pp. 6871,2012 .

[12] C.H. Jiao, D.D. Xia, J. Wang, L. Liu, W. Sheng, and P. Cheng, "Methods for determining the petrophysical property cutoffs of extra-low porosity and permeability sandstone reservoirs - an example from the Xishanyao Formation reservoirs in Yongjin oilfield", Oil and Gas Geology, vol. 30, pp. 379-383, 2009.

Received: January 25, 2015

Revised: March 01, 2015

Accepted: March 10, 2015

(c) Wu et al.; Licensee Bentham Open.

This is an open access article licensed under the terms of the Creative Commons Attribution Non-Commercial License (http://creativecommons.org/licenses/by-nc/4.0/) which permits unrestricted, non-commercial use, distribution and reproduction in any medium, provided the work is properly cited. 